Article

\title{
Hydrometeorological Drought Forecasting in Hyper-Arid Climates Using Nonlinear Autoregressive Neural Networks
}

\author{
Abdullah A. Alsumaiei *(D) and Mosaed S. Alrashidi ${ }^{(D)}$ \\ Civil Engineering Department, College of Engineering and Petroleum (COEP), Khaldiya Campus, \\ Kuwait University, P.O. Box 5969, Safat 13060, Kuwait; mosaed.alrashidi@ku.edu.kw \\ * Correspondence: alsumaiei.a@ku.edu.kw
}

Received: 2 August 2020; Accepted: 14 September 2020; Published: 18 September 2020

\begin{abstract}
Drought forecasting is an essential component of efficient water resource management that helps water planners mitigate the severe consequences of water shortages. This is especially important in hyper-arid climates, where drought consequences are more drastic due to the limited water resources and harsh environments. This paper presents a data-driven approach based on an artificial neural network algorithm for predicting droughts. Initially, the observed drought events in the State of Kuwait were tested for autocorrelation using the correlogram test. Due to the cyclic nature of the observed drought time series, nonlinear autoregressive neural networks (NARs) were used to predict the occurrence of drought events using the Levenberg-Marquardt algorithm to train the NAR models. This approach was tested for the forecasting of 12- and 24-month droughts using the recently developed precipitation index $(P I)$. Four statistical measures were used to assess the model's performance during training and validation. The performance metrics indicated that the drought prediction was reliable, with Nash-Sutcliffe values of $0.761-0.878$ during the validation period. Additionally, the computed $R^{2}$ values for model forecasts ranged between $0.784-0.883$, which indicated the quality of the model predictions. These findings contribute to the development of more efficient drought forecasting tools for use by water managers in hyper-arid regions.
\end{abstract}

Keywords: drought; artificial neural network; precipitation index; hyper-arid climate; autocorrelation

\section{Introduction}

Drought events are climatic phenomena featuring substantial reductions in precipitation over a defined period. Droughts may take place in all climatic zones and generally deplete water reserves at a slow pace (typically between several months to several years), significantly impacting the moisture levels in the soil, lakes, streams, and groundwater aquifers. Moreover, droughts affect human activities, such as agriculture. The global demand for freshwater has increased enormously over the past few decades due to rapidly increasing human populations and the demands of the ever-expanding agricultural and industrial sectors. Climate change and increasing water pollution have contributed to the need for drought management, particularly as the frequency of extreme hydrological events has increased in recent times [1,2]. Additionally, drought impacts can influence both society and the economy [3,4]. Water quality can also be affected by drought, as the quantities of sediments, nutrients, and organic matter carried by surface streams can experience significant decreases as flow rates fall [5]. Therefore, quantitative drought impact assessments should be conducted to establish resilient water management plans that can secure water resources for the growing human population.

Climate change has major implications for the future of humanity and represents a significant challenge for the global population, potentially causing more extreme global events that have major 
socioeconomic repercussions [6-8]. Climate change has attracted increasing worldwide attention from governments and researchers, where significant efforts have been invested in identifying strategies for reversing its outcomes. Due to the global warming effect, the impact of climate change is expected to increase in the future, leading to variability in sea surface temperature (SST) anomalies. This variability in the SST will certainly lead to more intense droughts events $[9,10]$. The impacts of droughts on arid regions are particularly concerning, as conventional water resources are severely limited in such regions, which generally receive $<250 \mathrm{~mm}$ per year of rainfall and whose water reserves are easily depleted. In these regions, groundwater is often the sole or major conventional water supply available, requiring efficient management (especially during water shortages). One method of addressing extreme climate change outcomes is through a risk management approach [11]. Unlike conventional methods, this takes a proactive approach that involves identifying and implementing solutions. Risk management can play a fundamental role in overcoming the problems associated with weather-related extremes and establishing systems that prevent further climate change [12].

Developing drought forecasting tools is a cornerstone component of risk management for water resource planning. In arid areas, drought forecast models help to evaluate how quickly groundwater can be recharged, providing a quantitative assessment of the anticipated impacts on water storage. Drought forecasting commonly uses data-driven stochastic methods. One of the most commonly used methods for this purpose involves generating autoregressive integrated moving average models (ARIMAs) [13-17]. These models are linear and have a limited capacity for forecasting nonlinear data. For the effective forecasting of nonlinear data, researchers have expanded the use of artificial neural networks (ANNs) with hydrological data over the past 25 years. In particular, the utility of ANNs in hydrological sciences includes forecasting drought events [18-27].

Khan et al. [28] utilized an ANN-based model to forecast hydrometeorological drought events in Malaysia's Langat River basin using wavelet transforms to preprocess raw precipitation data that were then used as the input of an ANN model to forecast droughts using the Standard Index of Annual Precipitation. Wavelet transforms effectively improved the ANN model predictions in comparison to non-processed precipitation data, leading the study to recommend the use of wavelet transforms for drought analysis purposes for more reliable results. However, the moist climatic region investigated in that study was very different from the harsh environmental conditions in arid regions, where the ability of wavelet transforms to improve ANN-based hydrological forecasts is limited [29].

Recent efforts in utilizing ANNs for operational hydrological drought forecasting were dedicated to developing reliable approaches for enhancing knowledge extraction from trained black box models. A recent study by Vidyarthi and Jian presented a novel approach for extracting operational forecasting outcomes for classifying droughts in the Indian subcontinent based on the Standardized Precipitation Index (SPI) [27]. The researchers relied on a decision tree support tool to establish simple rules for drought monitoring and forecasting. They showed that simple rules can be extracted from trained ANN models that can reliably aid policymakers in setting resilient operational decisions that can help with tolerating drought consequences. The researchers recommend that future studies should work on extensively developing ANN-based models that can be comprehensively utilized when managing water resource systems. Additionally, the researchers emphasized that the performance of their methods was excellent in the examined study area [27]. However, the global validity of ANN-based methods in other climatic regions should be thoroughly investigated before making generalized conclusions.

The cyclic nature of drought occurrences has prompted researchers to employ nonlinear autoregressive neural networks (NARs) in drought forecasting, as these combine the advantages of the ARIMA and ANN methods. For example, Belayneh et al. [30] used this approach to successfully forecast drought events in Ethiopia's Awash River basin using the SPI as a drought indicator. Despite the soundness of the SPI drought analysis capabilities, its computations require the normalization of precipitation data, including fitting to theoretical or empirical probability distributions. However, the goodness of fit is usually poor, especially for precipitation data in arid climates, where the time 
series include many null values, making the probabilistic distribution fitting highly problematic. Alsumaiei [31] has recently presented a precipitation index (PI) as a robust tool for drought analysis in arid climates and tested this PI in the arid State of Kuwait at 12- and 24-month time scales to assess the meteorological drought impacts on fresh groundwater reserves. That study showed that the PI provided similar drought assessment capabilities to the SPI but with the major advantage of not requiring precipitation data normalization, and thus providing a suitable drought analysis indicator for hyper-arid regions.

Data-driven techniques for forecasting droughts based on the utility of artificial neural networks have been shown to have powerful capabilities regarding making reliable forecasts. However, the implementation of NAR models in predicting drought occurrence in extremely harsh climatic conditions, such as those found in hot and dry areas, has not been thoroughly examined. The major objective of the current study was to bridge this gap. The study employed the PI to construct an NAR-based drought forecast model using historical precipitation records in Kuwait; we then validated the model when predicting 12- and 24-month droughts from 1992-2020. The correlogram test was used on the observed PI time series to determine the significant number of autoregressive terms in the NAR model. The results contribute to water resources risk management in arid and hyper-arid regions by developing a reliable drought forecasting tool that can provide early warnings of upcoming droughts, which can aid water managers in developing resilient water-supply plans in water-shortage scenarios.

\section{Materials and Methods}

\subsection{Study Area}

Kuwait is one of the smallest countries in the Arabian Gulf, with a total area of $17,818 \mathrm{~km}^{2}$ and $195 \mathrm{~km}$ of coastline (Figure 1). The country has a hyper-arid climate and suffers from extremely dry and hot summer months (from May to August), where the temperatures range from $40-50{ }^{\circ} \mathrm{C}$ with an average annual precipitation of $115.7 \mathrm{~mm}$ [31,32]. During this season, increased evaporation rates lead to high water stress, while during June and July northwesterly winds can cause extreme sandstorms.

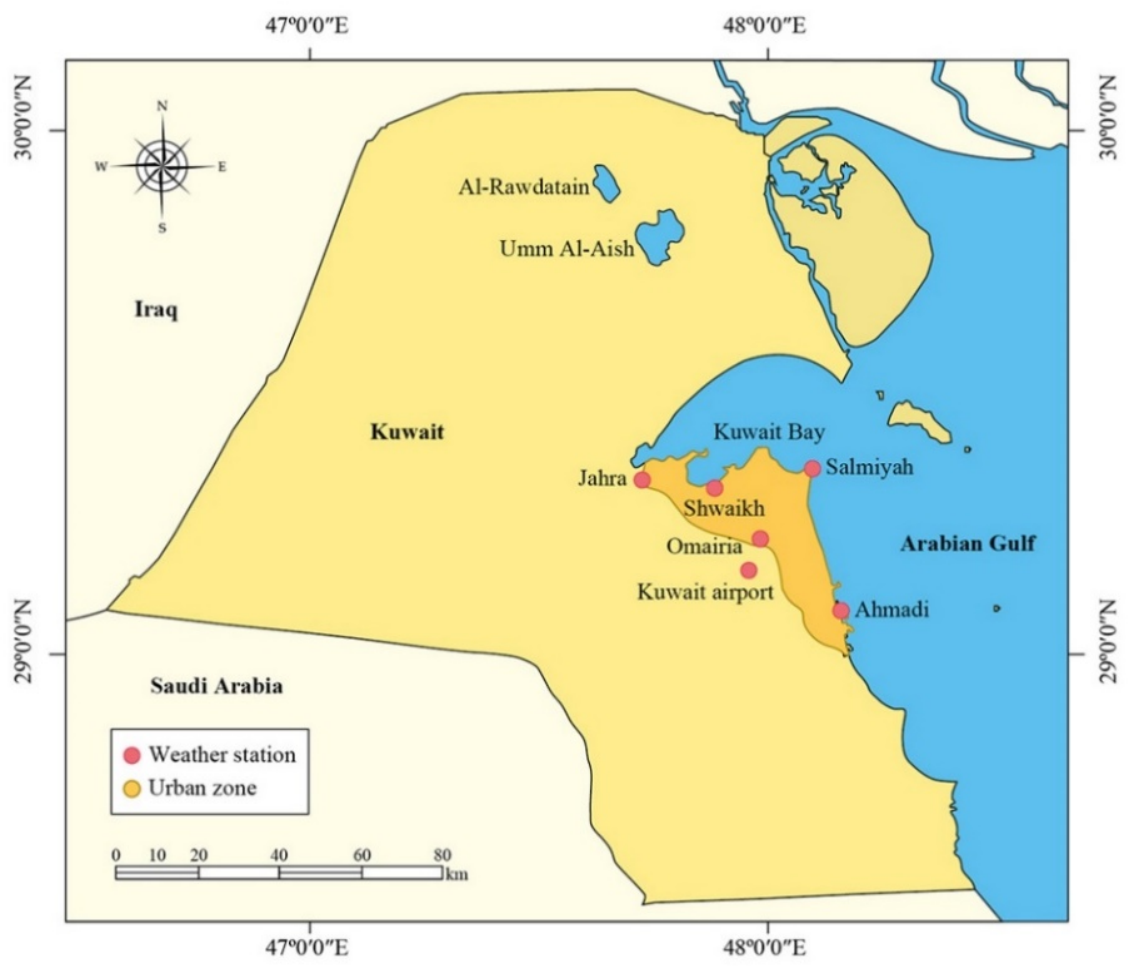

Figure 1. Locations of urban areas, weather stations, and major groundwater aquifers in Kuwait. 
Like all western Arabian Gulf countries, Kuwait suffers from a lack of natural water resources due to the lack of surface water bodies, such as rivers and lakes. The availability of fresh groundwater is also limited. Natural sources of usable water exist in the Al-Rawdatain and Umm Al-Aish aquifers in northern Kuwait [33]. However, the water in the Umm Al-Aish aquifer was contaminated by an oil spill in 1990 [34,35]. Other aquifers are present in the southwestern part of the country, but the water is brackish and cannot be used without treatment. Moreover, the water demand has rapidly increased in recent years due to a high population growth rate from 1.25-8.6\% [36]. Kuwait's oil reserves of $>104$ billion barrels mean that oil wealth currently supports the use of economically unviable water purification methods to supply its population and fertile land, including seawater desalination using distillation and reverse osmosis, along with wastewater treatment for reuse [37].

Such diminishing water sources and increasing water requirements make it necessary to accurately predict the drought status in Kuwait. Figure 2 presents annual and monthly rainfall data from 1992-2019 that were collected from the Kuwait International Airport (KIA). These are the only available meteorological records with continuous historical rainfall that can be used for drought analysis. As rainfall records from weather stations across other urban areas in Kuwait are spatially correlated [38], the KIA data can be used to analyze the drought status in Kuwait.

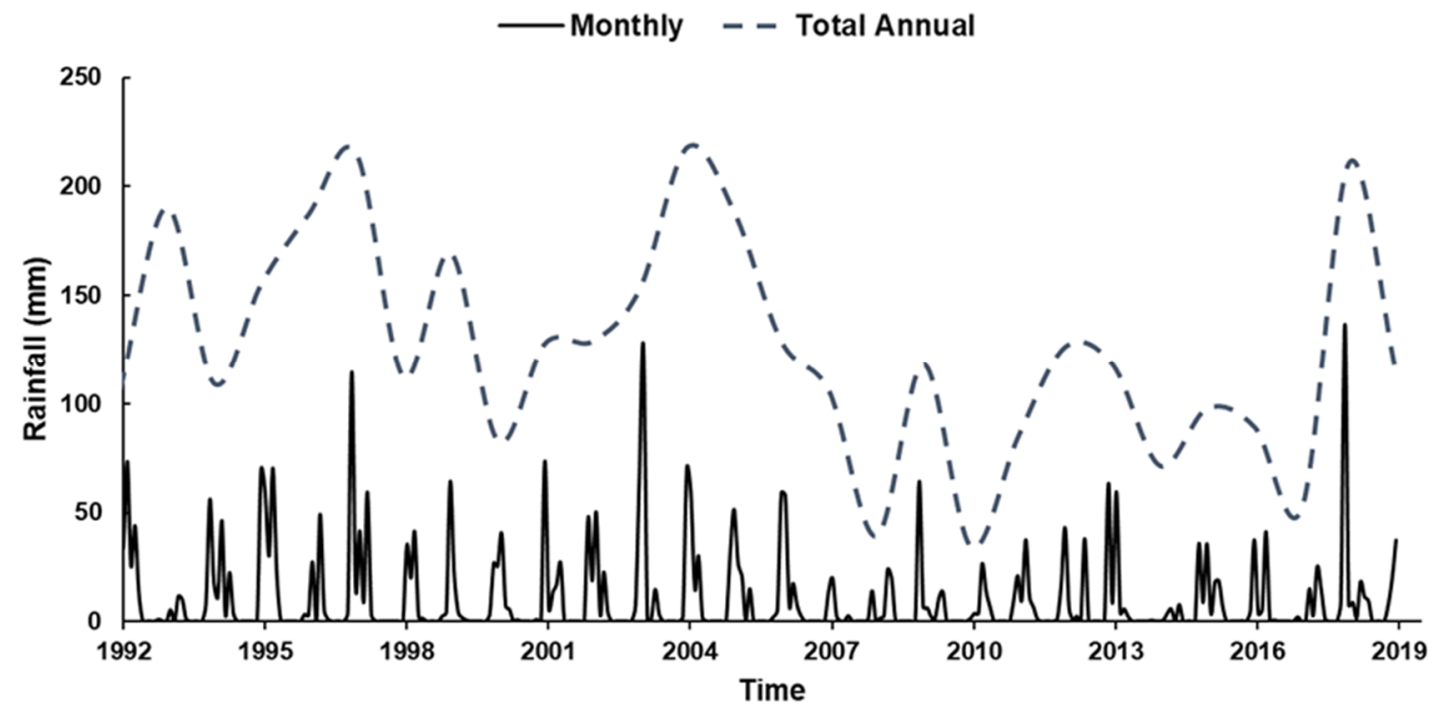

Figure 2. Total annual and monthly precipitation at the Kuwait International Airport (KIA) weather station from 1992-2019.

\subsection{Drought Analysis Using the PI}

The PI was presented by Alsumaiei [31] as a surrogate drought index for the SPI [39]. The PI is a meteorological drought index that resembles the error equation; it is computed using the following equation:

$$
P I=\frac{P-\bar{P}}{\bar{P}}
$$

where $P$ is the precipitation and $\bar{P}$ is the average precipitation. For example, extreme drought conditions $(P=0)$ produce a $P I$ of -1 , average precipitation produces a $P I$ of 0 , and twice the average precipitation produces a PI of 1 . Table 1 lists drought categories according to their PI value. The definition of the original SPI was equivalent to a Z-score for a normal probability deviation, while the PI represents an evaluation of the precipitation deficit, which is divided by the long-term average in a way that relaxes the normalization requirements. 
Two measures of the drought extent are important for achieving an objective drought assessment using this method. First, the cumulative magnitude of a drought is calculated using the drought severity $S$ with $P I$ values below zero for every consecutive occurrence:

$$
S=-\sum_{i=1}^{x} P I_{i}
$$

where $i$ is a drought occurrence and $x$ is the total consecutive drought occurrences. In Equation (2), the negative sign is added for the sake of convenience such that $S$ becomes positive. Although Table 1 defines a drought as occurring when $P I<-0.5$, the severity calculation is undertaken when $P I$ is below 0 . Second, the drought duration $d$ represents the time during which severe drought takes place. Similar to severity, drought duration is calculated using PI values below 0 . Droughts lasting for only one month are ignored, as they frequently occur before the start of the rainfall season due to the long zero-rainfall period during summer.

Table 1. Precipitation index $(P I)$ drought classifications.

\begin{tabular}{cc}
\hline Drought Description & PI Value \\
\hline Extremely wet & $>1.0$ \\
Very wet & 0.75 to 1.0 \\
Moderately wet & 0.5 to 0.75 \\
Normal & 0.5 to -0.5 \\
Moderate drought & -0.5 to -0.75 \\
Severe drought & -0.75 to -1.0 \\
Extreme drought & -1.0 \\
\hline
\end{tabular}

\subsection{Nonlinear Autoregressive Networks}

\subsubsection{Network Structure}

NARs are unique networks of ANNs, which were inspired by information processing in human neural systems. ANNs comprise simple processing units called nodes with specific neuron connections. During the training process, each neuron is allocated a weight to provide the best fit between the input and output data (targets). ANNs can be classified based on the direction in which the data flows [40]. Feedforward neural networks (FNNs) have a layered node arrangement in which the input layer receives data, which are then sent through hidden layers to a final output layer; the information flow is normally unidirectional. A special type of FNN is a recurrent neural network (RNN), in which the flow information is bidirectional due to the outputs being reused.

An NAR is a particular form of RNN used for describing processes based on lagged input/output variables. NARs are a combination of ANNs and autoregressive models (ARs), which are a widely employed statistical method for analyzing and modeling time series. Combining these elements in an NAR makes it capable of capturing nonlinear behavior within an autoregressive time series. Figure 3 demonstrates a conceptual illustration of an NAR.

A standard formulation for NAR models is:

$$
y(t)=f\left(\left(y(t-1), y(t-2), \ldots, y\left(t-n_{y}\right)\right),\right.
$$

where $y(t)$ is the target time series, $n_{y}$ is the target delay term, and $f$ is a nonlinear function, which is usually unknown. Thus, Equation (3) predicts the next time step value based on the past values according to target delay terms.

The number of hidden layers is calibrated to regress the black box function to the target time series; then, the input time series is passed through a specified number of hidden layers using a black 
box function. A specific algorithm is used to train the NAR network to find the optimal match between inputs and target variables.

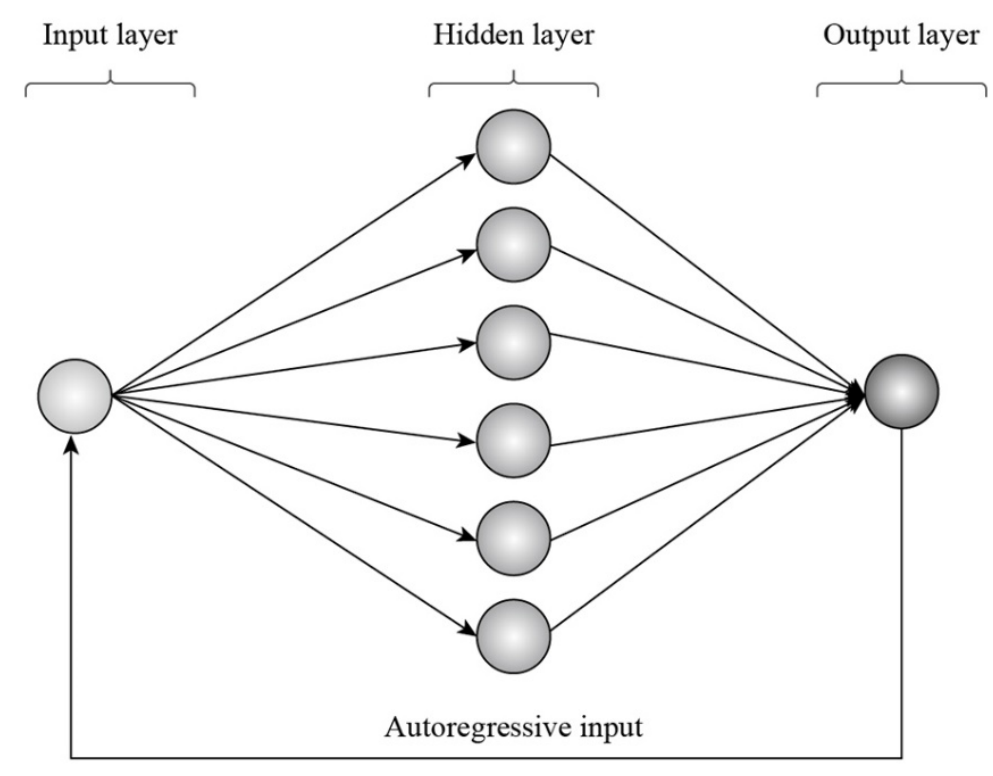

Figure 3. Conceptual illustration of a nonlinear autoregressive neural network (NAR).

\subsubsection{Training Algorithms}

The NAR training process employed the Levenberg-Marquardt (LM) backpropagation algorithm, which is a well-established training method that has been widely utilized in ANN-based hydrological models [41-45]. In this method, the input variable is passed through the hidden layers toward the output layer. After the error is computed, the input variable is recycled back to the input layer after being modified with a weight. This helps the LM algorithm effectively search for function minima and provides an optimized solution, making it suitable for training autoregressive networks.

\subsection{Autocorrelation Analysis}

A key element of autoregressive models is their employment of autocorrelation within the observed data when making forecasts, making it essential to conduct a correlogram test on the observed precipitation index time series to assess the level of correlation for adjacent values. The temporal separation period is known as the lag $(\tau)$. Initially, the observed time series of the precipitation index is standardized using Equation (4):

$$
Z_{j}=\frac{P I_{j}-\mu}{\sigma}
$$

where $P I$ is the precipitation index value at month $j, \mu$ is the precipitation index time series arithmetic average, and $\sigma$ is the precipitation index time series standard deviation. The correlogram $r$ is computed for the standardized data $Z_{j}$ at lag $\tau$ according to Equation (5):

$$
r_{\tau}=\frac{n}{n-\tau} \frac{\sum_{j=1}^{n-\tau}\left(Z_{j}-Z\right)\left(Z_{j+\tau}-\bar{Z}\right)}{\sum_{j=1}^{N}\left(Z_{j}-\bar{Z}\right)^{2}}
$$

where $\bar{Z}$ is the arithmetic mean and $n$ is the number of values in the standardized series $Z_{j}$. The correlogram's lower and upper limits are -1 and +1 , respectively. The confidence bounds 
(CBs) are represented by the upper and lower lines drawn on the correlogram, in which the significance level is defined by the confidence lines with a significance level of $\alpha=0.05$ :

$$
\mathrm{CB}= \pm \frac{z_{1-\alpha / 2}}{\sqrt{n}}
$$

where $z$ denotes the quartile function of the standard normal distribution. A significant autocorrelation exists within the PI time series if the computed correlogram exceeds the designated significance limits.

\subsection{Model Validation and Statistical Evaluation}

Validation of the NAR model was conducted using the chronological division of observed data into two subsets: training and validation. The NAR performance was assessed using four performance metrics: the Nash-Sutcliffe coefficient (NASH), the mean absolute error (MAE), the Pearson correlation coefficient, and the coefficient of determination $\left(R^{2}\right)$. The latter demonstrates how strongly the observed and simulated targets are associated; it has a range between 0 (no statistical association) and 1 (an exact match between the simulated and observed targets). $R^{2}$ represents the square of the Pearson correlation coefficient $(R)$; it does not directly measure prediction accuracy (as $R$ does), but rather assesses how good a predictor can be built using the model. The $R^{2}$ for both the observed and forecasted precipitation index values were calculated using:

$$
R^{2}=\left(\frac{\sum_{i=1}^{n}\left(\text { PIo }_{i}-\overline{P I o}\right)\left(\text { PIf }_{i}-\overline{P I f}\right)}{\sqrt{\sum_{i=1}^{n}\left(\text { PIo }_{i}-\overline{P I o}\right)^{2}} \sqrt{\sum_{i=1}^{n}\left(\text { PIf }_{i}-\overline{P I f}\right)^{2}}}\right)^{2}
$$

where $P \mathrm{Po}_{i}$ is the observed precipitation index for time step $i, \mathrm{PIf}_{i}$ is the forecasted precipitation index for time step $i, \overline{P I o}$ is the mean for the observed precipitation index time series, $\overline{P I f}$ is the mean for the forecasted precipitation index time series, and $n$ is the number of time steps within the validation period.

The MAE was used to quantify the variation between the forecasted targets and the observations in an objective fashion, as follows:

$$
\mathrm{MAE}=\frac{1}{n} \sum_{i=1}^{n}\left|P \mathrm{Io}_{i}-\mathrm{PIf}_{i}\right|
$$

NASH is widely used within hydrological modeling [46]; it has a range from $-\infty$ to 1 , with values $<0$ showing that the observed data arithmetic average is a superior predictor than the forecasted data. NASH was calculated as follows:

$$
\mathrm{NASH}=1-\frac{\frac{1}{n} \sum_{i=1}^{n}\left(\mathrm{PIo}_{i}-\mathrm{PIf}_{i}\right)^{2}}{\frac{1}{m} \sum_{i=1}^{m}\left(\mathrm{PIo}_{i}-\overline{\mathrm{PIo}}\right)^{2}},
$$

where $m$ denotes the number of time steps in the observation period.

Equation (9) ensured that the model's performance in the validation period was assessed by NASH relative to the variation from the mean for the full observation dataset. Using NASH to assess the model ensured adequate representation for the modeled system's variability at any point for NASH values $>0$.

\subsection{Drought Forecasting Procedures}

The computational procedures for drought forecasting first computed the observed PI time series based on the precipitation data according to Equation (1). The computed PI time series was then tested for autocorrelation to determine the significant number of autocorrelation lags. The feedback 
delay term in Equation (3) was then selected according to the significant number of lags. The NAR model parameters (number of hidden layers and number of epochs) were then arbitrarily selected. The network parameters could be calibrated to optimize the model performance based on the statistical evaluation metrics. When acceptable statistical performance metrics were achieved, the constructed NAR model could then be used for the PI predictions. Figure 4 depicts the computational methodology used for the drought forecasting in this current study.

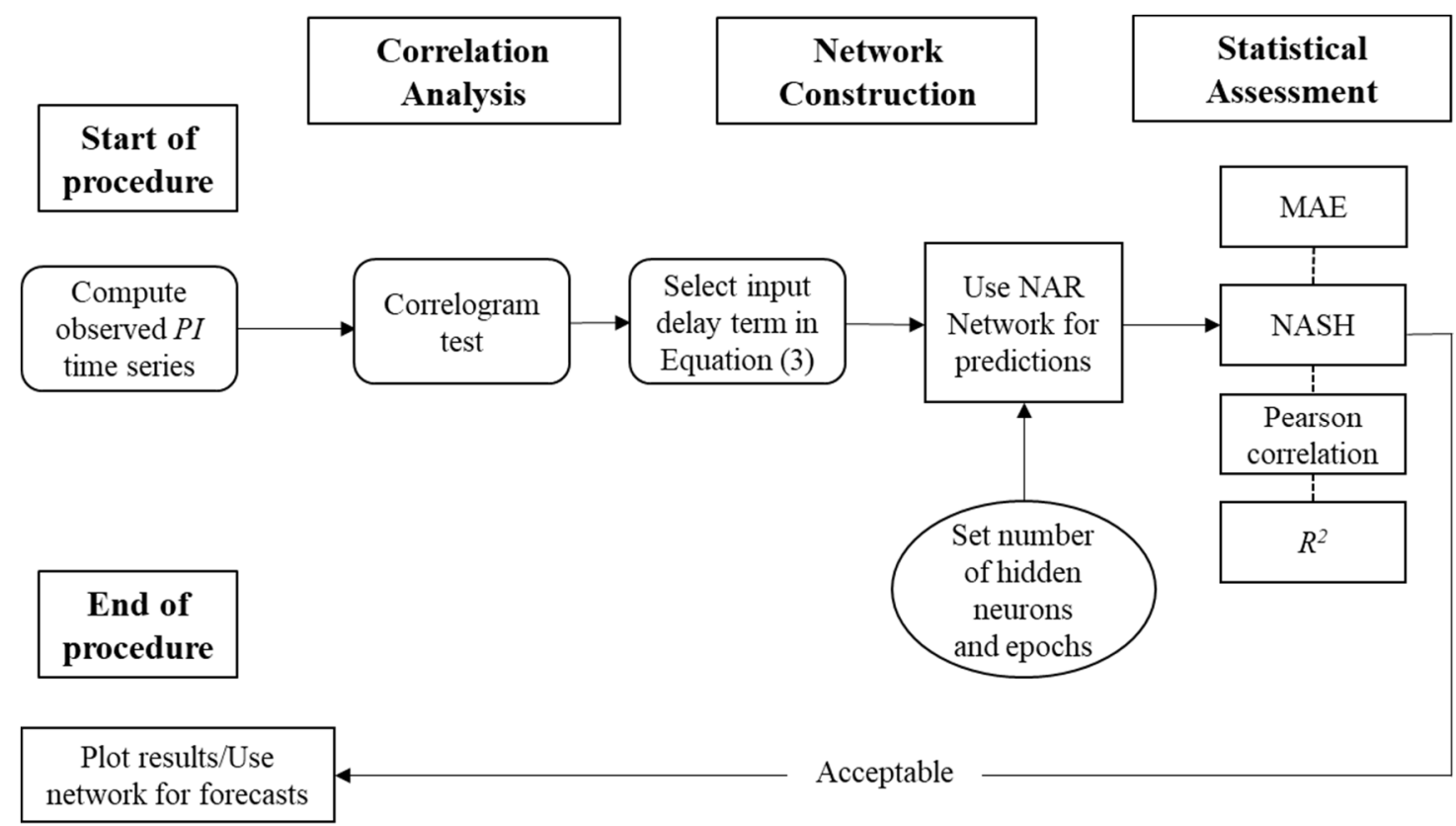

Figure 4. Flowchart illustrating the computational procedures for drought forecasting. MAE: mean absolute error, NASH: Nash-Sutcliffe coefficient.

\section{Results and Discussion}

\subsection{NAR Drought Forecasting Model}

The first step in developing autoregressive models is testing the target data for autocorrelation. Figure 5 shows the correlogram test results for the observed 12- and 24-month precipitation index time series for the study area. The figure boundaries designate the upper and lower significance boundaries, beyond which, significant autocorrelations exist. Determining the significant number of autocorrelation lags is essential for determining the number of autoregressive terms to use in Equation (3). Both time series clearly exhibited strong autocorrelations, with $P I_{12}$ showing a significant autocorrelation up to 9 months and $\mathrm{PI}_{24}$ up to 35 months. Accordingly, the autoregression terms in the drought forecasting models were set to 9 and 35 months for $P I_{12}$ and $P I_{24}$, respectively. The NAR model predicted the next time step drought index based on the past 9 and 35 months' values for the $P I_{12}$ and $P I_{24}$ time series, respectively. The relatively high number of autoregressive terms in the forecast model, especially at the 24-month scale, provided the model with an early detection capability for upcoming drought events. This feature will assist water managers in developing resilient water governance plans to cope with anticipated water-shortage scenarios.

The number of hidden layers and the number of epochs for the autoregressive neural network models were set to 10 . The NARs were constructed using 10 epochs. The best NAR validation performance was achieved at epoch 4 (Figure 6). The observed drought indices' data series were calculated using the observed rainfall data at KIA station between October 1992 and April 2020 at 12- and 24-month scales. The observed drought data were used to construct the NAR models. The data were chronologically divided into subsets of 80 and 20\% for training and validation purposes, 
respectively. Figure 7 shows the NAR modeling results for the drought indices at 12- and 24-month scales. The NAR models were found to efficiently represent the long-term variations in the drought index. The long-term trend and periodic drought behavior were well represented at the temporal scales examined.
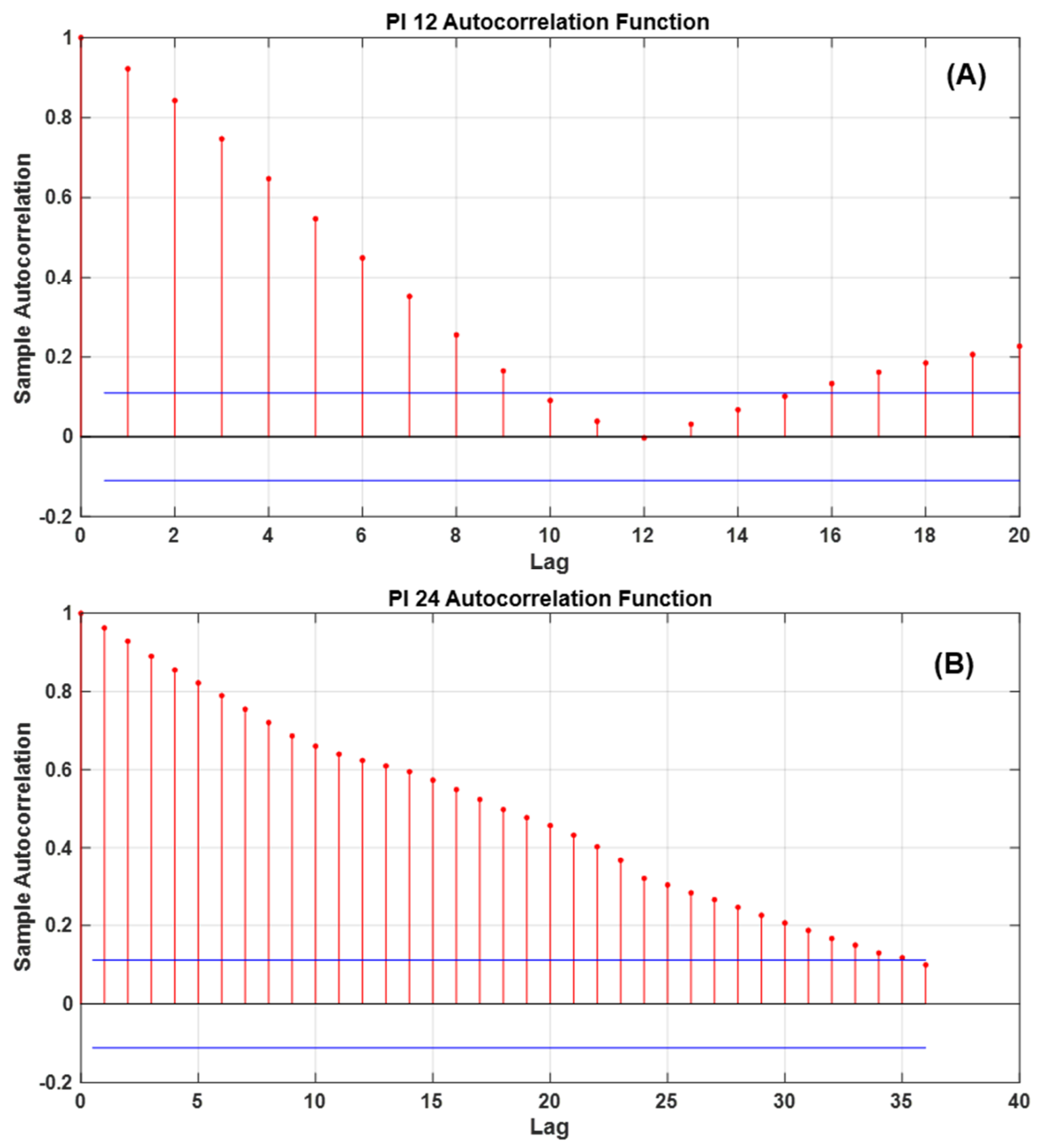

Figure 5. Correlogram test results for the (A) 12-month and (B) 24-month observed precipitation index time series for the study area. 

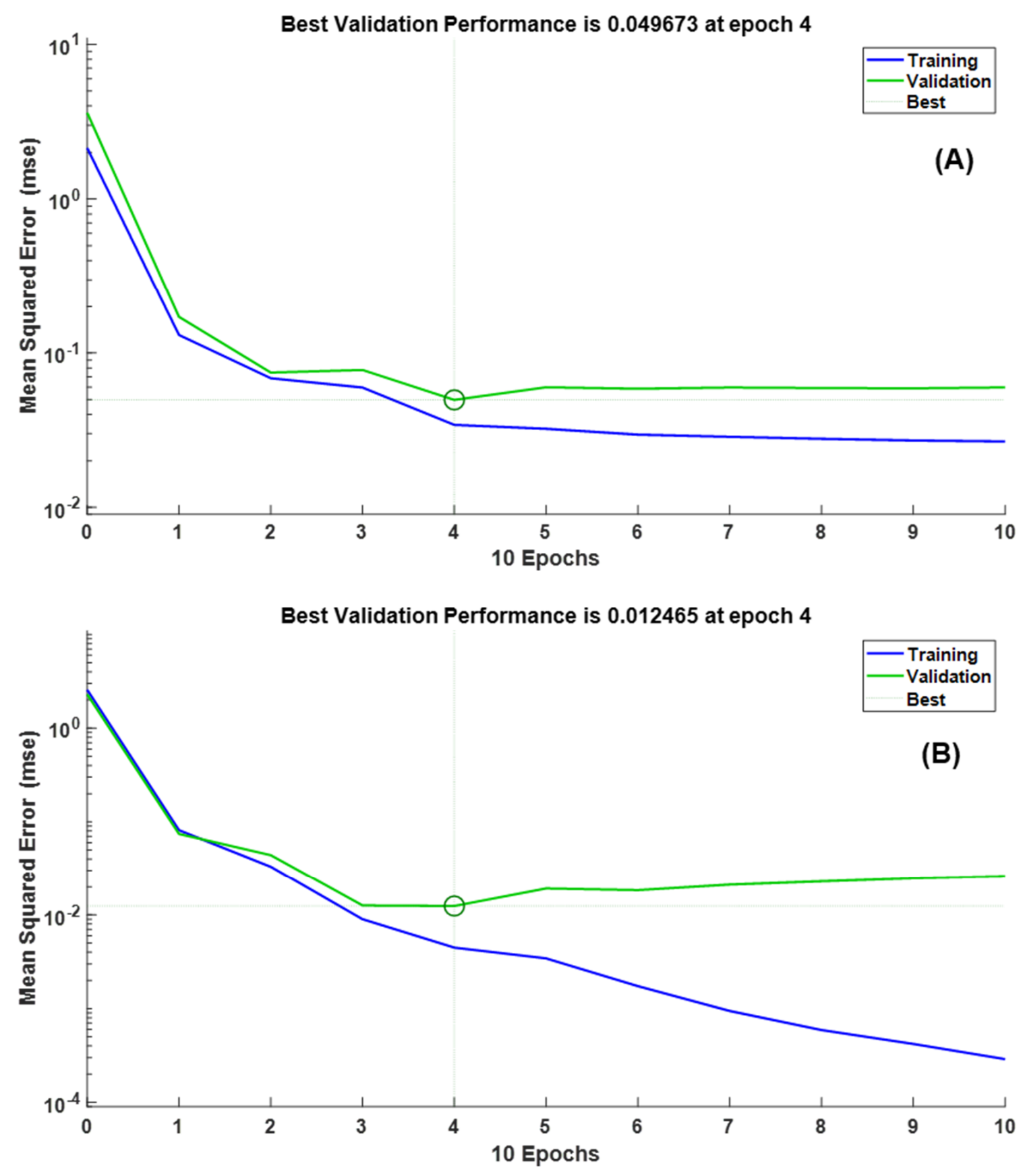

Figure 6. Variations in the mean squared error for different epochs in the training and validation periods for the (A) 12-month and (B) 24-month drought forecast models. 

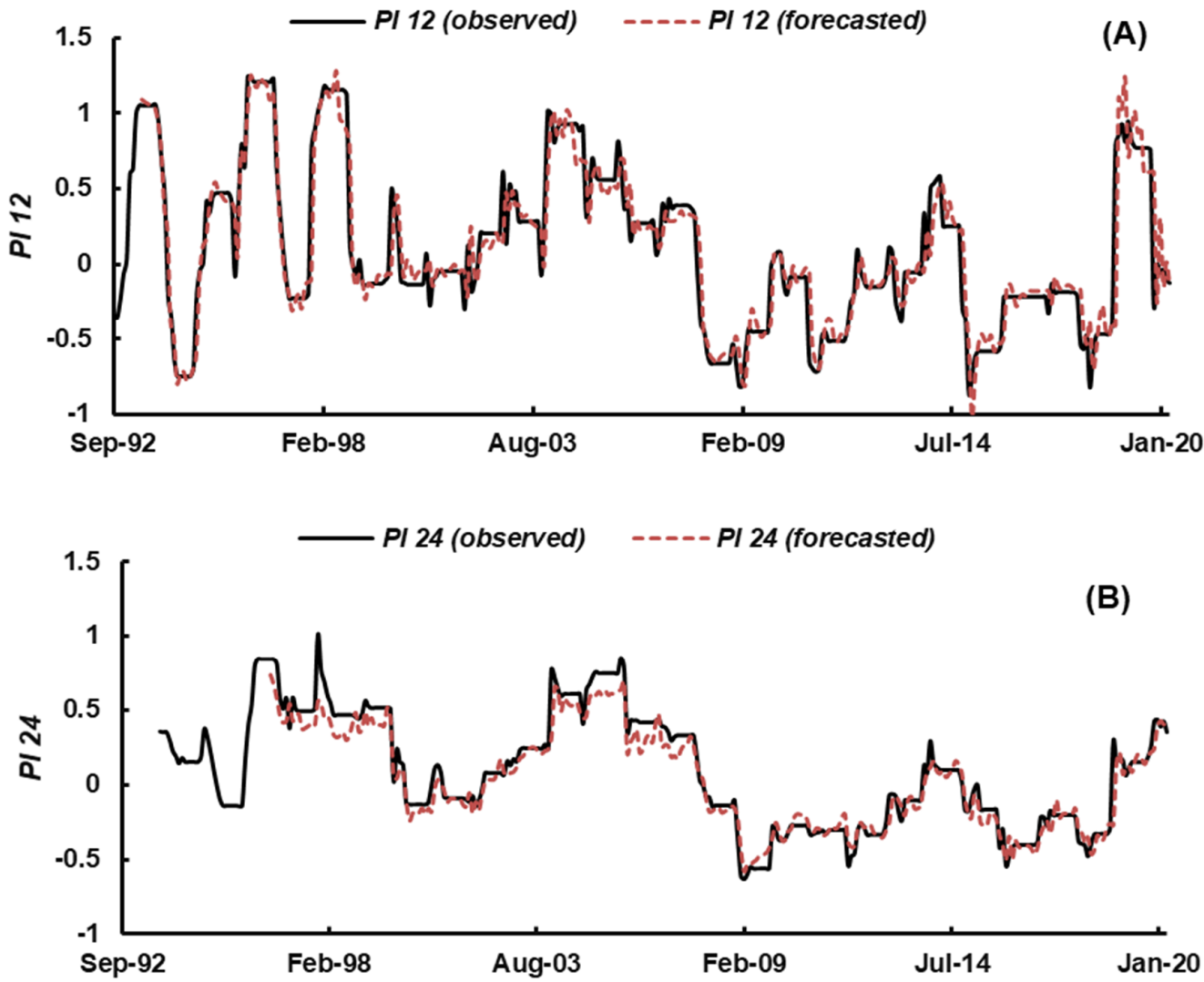

Figure 7. Observed and forecasted PI time series for the (A) 12-month and (B) 24-month drought forecast models.

Table 2 lists the evaluation metrics used for the NAR model's assessment. The computed statistical metrics indicated a better model performance in the training period than the validation period. This was logical as the models were optimized to match the target data during the training period. However, the reduction in the evaluation metric values during the validation period was considered minimal; therefore, the possibility of the model overfitting within the validation period can be rejected. Additionally, the NAR model efficiency when forecasting 24-month droughts was greater than the efficiency when forecasting 12-month droughts. This can be explained by considering the rainfall time series variability. For longer drought time scales ( 24 months in this case), the rainfall time series exhibited less variability in comparison with shorter time scales (12 months in this case). Accordingly, the NAR model was better at detecting the time series variability at the 24-month scale, resulting in better model performance. Furthermore, it is worth noting that the Pearson correlation coefficients and the coefficient of determination values were close to perfect match values. This indicated that the developed models could adequately represent the association between the input and output data. Hence, reliable predictions can be generated from the models. Additionally, the computed errors were found to be minimal, which objectively indicates the quality of the models.

Table 2. Statistical evaluation measures for the 12- and 24-month drought forecast models.

\begin{tabular}{ccccc}
\hline \multirow{2}{*}{ Evaluation Measure } & \multicolumn{2}{c}{ 12-Month } & \multicolumn{2}{c}{ 24-Month } \\
\cline { 2 - 5 } & Training & Validation & Training & Validation \\
\hline NASH & 0.893 & 0.761 & 0.931 & 0.878 \\
Correlation & 0.945 & 0.886 & 0.981 & 0.940 \\
$R^{2}$ & 0.893 & 0.784 & 0.963 & 0.883 \\
MAE & 0.108 & 0.142 & 0.076 & 0.058 \\
\hline
\end{tabular}


Figure 8 presents the forecasted versus observed precipitation indices at the 12- and 24-month time scales, which are plotted with the perfect match line $(y=x$ line) for comparison. The random distribution of points relative to the $y=x$ line shows that no bias in the predictions occurred, which signifies the model's reliability and that prediction biases were eliminated. As the 24-month drought index time series had less long-term variability, it also had a smoother scattering of points.
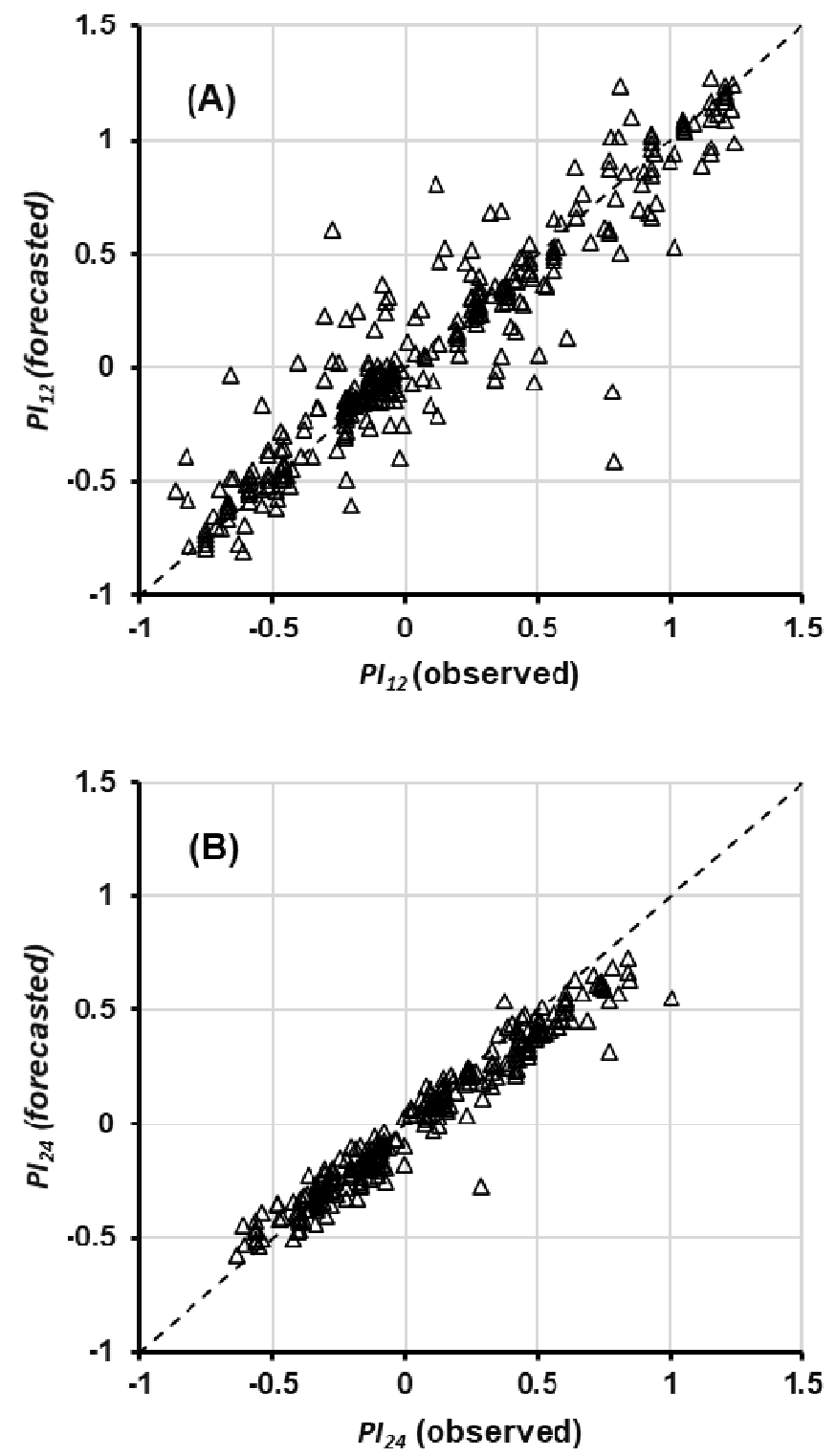

Figure 8. Forecasted vs. observed precipitation indices for the (A) 12-month and (B) 24-month scale models.

An essential feature of any drought forecasting model is its ability to robustly predict drought severities and durations. Equation (2) was used to compute the observed and forecasted drought severities at the 12- and 24-month time scales. Additionally, the drought durations were calculated for periods when the precipitation index was $<0$. Table 3 compares the computed and observed drought severities and durations. The NAR-based forecast models efficiently represented the drought duration and severity for the examined time scales, indicating that the NAR-based approach represents a powerful and reliable drought forecasting tool that can aid water managers when planning for anticipated droughts and possible water-shortage scenarios. 
Table 3. Observed and forecasted drought severities and durations for 12- and 24-month drought time scales.

\begin{tabular}{cccc}
\hline \multicolumn{2}{c}{ Drought Scale } & $\begin{array}{c}\text { Average Drought } \\
\text { Severity }\end{array}$ & $\begin{array}{c}\text { Average Drought } \\
\text { Duration (Months) }\end{array}$ \\
\hline \multirow{2}{*}{$P I_{12}$} & Observed & 4.2 & 13.4 \\
& Forecasted & 4.4 & 15 \\
\multirow{2}{*}{$P I_{24}$} & Observed & 7.5 & 30 \\
& Forecasted & 9.2 & 36 \\
\hline
\end{tabular}

\subsection{Comparisons with Previous Studies}

It essential to consider the NAR model's performance in the context of previous attempts of developing drought forecasting models. Almedeij [47] developed a stochastic periodic model to forecast drought occurrences in the study area using SPI. This model showed a considerable ability for forecasting long-term trends in drought occurrences, but a notable deficiency in detecting short-term droughts. The need for short-term forecasts is vital for water resource planners to develop resilient water-supply plans. A basic premise of the autoregressive model developed here is the capability to conduct short-term predictions. The results of the current study showed that the NAR model was superior to periodic models for short-term water management.

The current study's results can also be compared with previous studies that used artificial intelligence methods to forecast drought occurrences. A key feature of the current model is the relatively long lead time for the recursive neural network. The autocorrelation analysis shown in Figure 5 demonstrated significant autocorrelations (up to 9 and 35 months) in the 12- and 24-month drought time series, respectively, enabling the constructed model to provide early warnings of anticipated droughts. In comparison, Belayneh et al. [30] showed that autoregressive neural networks were efficient at forecasting the SPI drought index over 6 and 12 months in advance. The statistical assessment measures for the constructed NAR model (Table 2) were comparable with previous drought forecasting studies using ANN approaches (e.g., [28,30]).

\subsection{Drought Forecasting in Hyper-Arid Climates}

As the study area receives no precipitation from June to August and rainfall is exceedingly rare during May and September, the high frequency of no-rainfall months makes the probability distribution for the precipitation time series highly abnormal. Most existing drought indices require the normalization of precipitation data, making their use in arid climates problematic. In contrast, the drought forecast model developed here is based on the PI, which does not require fitting a probability distribution to the rainfall data. This makes it a more reliable index for drought analysis in arid climates.

As groundwater represents the only readily available water resource in the study area, developing efficient drought monitoring and forecasting tools relative to drought impacts on groundwater aquifers is highly important. A key element of the drought analysis process is the selection of an appropriate drought index time scale. The longer time scales (12 and 24 months) used in this study are more suitable for characterizing drought impacts on groundwater resources. Groundwater aquifers respond slowly to rainfall shortages [48]; therefore, shorter drought analysis scales (e.g., 1-6 months) would certainly fail to present the true drought status given Kuwait's long annual zero-rainfall period, making their usage for drought analysis meaningless.

\subsection{Model Generalizability, Limitations, and Potential Improvements}

The artificial-intelligence-based recursive model presented here was clearly efficient and effective at making reliable drought forecasts under the considered experimental conditions. However, in general, data-driven models applied to the analysis of hydrological processes should be done with caution. The model developed in the current study was site-specific; therefore, its potential application at 
other sites might require recalibration of network parameters, especially the feedback delay term, which is based on the autocorrelation analysis. Another limitation of the constructed model is its reliance on the periodic behavior of the drought time series. For example, the model does not account for other anthropogenic stresses on water resources that may accelerate the occurrence of drought events. Furthermore, the model was developed for a hyper-arid region; therefore, applying it to other climatic regimes requires consideration of other factors that could be more attributable to droughts in the target climatic region (e.g., irrigation of agricultural lands). Overall, though, the application of a data-driven approach was powerful and robust when forecasting drought events in the study area. In particular, managing water resources in such a harsh environment is crucial due to water scarcity; therefore, future research should be dedicated to exploring and enhancing data-driven approaches when monitoring and forecasting droughts in such water-limited regions.

\section{Conclusions}

This study investigated the application of an NAR model and the PI to forecasting drought events in a hyper-arid climate, using historical rainfall in Kuwait (KIA station) from 1992-2020 for the model construction and validation. The NAR methodology was both efficient and reliable at forecasting short-term drought events and clearly outperformed other periodic models developed for the same study area regarding short-term drought prediction. Moreover, the NAR model was able to efficiently represent long-term trends in observed drought events. A notable improvement in the drought forecasting ability was found for the 24-month drought forecast model in comparison with the 12-month model. This is due to less long-term variability in the 24-month drought index time series. The NAR model forecasted droughts in hyper-arid climates with similar efficiency to other ANN-based methods for drought forecasting in other climatic regions. Despite the robust performance of the presented NAR model, caution should be taken when applying it to other study sites, as the recalibration of network parameters might be needed.

Water resources in hyper-arid regions are severely limited, making the development of drought monitoring and forecasting tools vital for setting resilient water-supply plans during water-shortage periods. These tools are a cornerstone element when managing limited but readily available water resources in such regions. Future studies should work on extending these findings by further examining the validity of data-driven methods when forecasting drought events at local and regional scales. An especially appealing feature of using data-driven models for water management is the simplicity of computations using readily available meteorological data. Additionally, the use of these methods is appropriate in cases when the practical implications of predictions are more important than understanding the physical mechanisms of the hydrological processes involved.

Author Contributions: Conceptualization, A.A.A.; data curation, A.A.A. and M.S.A.; formal analysis, A.A.A.; investigation, A.A.A.; methodology, A.A.A.; project administration, A.A.A.; resources, A.A.A. and M.S.A.; software, A.A.A.; supervision, A.A.A.; validation, A.A.A.; visualization, A.A.A. and M.S.A.; writing-original draft, A.A.A.; writing-review and editing, A.A.A. and M.S.A. All authors have read and agreed to the published version of the manuscript.

Funding: This research received no external funding.

Conflicts of Interest: The authors declare no conflict of interest.

\section{References}

1. Stott, P.A. How climate change affects extreme weather events. Science 2016, 352, 1517-1518. [CrossRef] [PubMed]

2. Yuan, X.-C.; Wei, Y.-M.; Wang, B.; Mi, Z. Risk management of extreme events under climate change. J. Clean. Prod. 2017, 166, 1169-1174. [CrossRef]

3. Ziolkowska, J.R. Socio-Economic Implications of Drought in the Agricultural Sector and the State Economy. Economies 2016, 4, 19. [CrossRef] 
4. Kilimani, N.; Van Heerden, J.H.; Bohlmann, H.; Roos, L. Economy-wide impact of drought induced productivity losses. Disaster Prev. Manag. Int. J. 2018, 27, 636-648. [CrossRef]

5. Mosley, L.M. Drought impacts on the water quality of freshwater systems; review and integration. Earth-Sci. Rev. 2015, 140, 203-214. [CrossRef]

6. Field, C.B.; Barros, V.; Stocker, T.F.; Dahe, Q. Managing the Risks of Extreme Events and Disasters to Advance Climate Change Adaptation: Special Report of the Intergovernmental Panel on Climate Change; Cambridge University Press: Cambridge, UK, 2012; ISBN 1107025060.

7. Rummukainen, M. Changes in climate and weather extremes in the 21st century. Wiley Interdiscip. Rev. Clim. Chang. 2012, 3, 115-129. [CrossRef]

8. Yuan, X.-C.; Lall, U.; Mi, Z.; Wei, Y.-M.; Sun, X.; He, J. China's socioeconomic risk from extreme events in a changing climate: A hierarchical Bayesian model. Clim. Chang. 2016, 139, 169-181. [CrossRef]

9. Trenberth, K.E.; Dai, A.; Van Der Schrier, G.; Jones, P.D.; Barichivich, J.; Briffa, K.R.; Sheffield, J. Global warming and changes in drought. Nat. Clim. Chang. 2013, 4, 17-22. [CrossRef]

10. Seager, R.; Kushnir, Y.; Ting, M.; Cane, M.; Naik, N.; Miller, J.; Henderson, N. Would Advance Knowledge of 1930s SSTs Have Allowed Prediction of the Dust Bowl Drought? J. Clim. 2008, 21, 3261-3281. [CrossRef]

11. Nam, W.-H.; Choi, J.-Y.; Yoo, S.-H.; Jang, M.-W. A decision support system for agricultural drought management using risk assessment. Paddy Water Environ. 2012, 10, 197-207. [CrossRef]

12. Kunreuther, H.; Heal, G.; Allen, M.; Edenhofer, O.; Field, C.B.; Yohe, G. Risk management and climate change. Nat. Clim. Chang. 2013, 3, 447-450. [CrossRef]

13. Mishra, A.K.; Desai, V.R. Drought forecasting using stochastic models. Stoch. Environ. Res. Risk Assess. 2005, 19, 326-339. [CrossRef]

14. Sahu, R.K.; Mishra, S.K.; Eldho, T.I.; Jain, M. An advanced soil moisture accounting procedure for SCS curve number method. Hydrol. Process. 2007, 21, 2872-2881. [CrossRef]

15. Han, P.; Wang, P.X.; Zhang, S.Y.; Zhu, D.H. Drought forecasting based on the remote sensing data using ARIMA models. Math. Comput. Model. 2010, 51, 1398-1403. [CrossRef]

16. Han, P.; Wang, P.; Tian, M.; Zhang, S.; Liu, J.; Zhu, D. Application of the ARIMA Models in Drought Forecasting Using the Standardized Precipitation Index. In Proceedings of the Integrity and Internal Control in Information Systems; Springer Science and Business Media LLC: Berlin/Heidelberg, Germany, 2013; Volume 392, pp. 352-358.

17. Tian, M.; Wang, P.; Khan, J. Drought Forecasting with Vegetation Temperature Condition Index Using ARIMA Models in the Guanzhong Plain. Remote Sens. 2016, 8, 690. [CrossRef]

18. Mishra, A.K.; Desai, V. Drought forecasting using feed-forward recursive neural network. Ecol. Model. 2006, 198, 127-138. [CrossRef]

19. Morid, S.; Smakhtin, V.; Bagherzadeh, K. Drought forecasting using artificial neural networks and time series of drought indices. Int. J. Clim. 2007, 27, 2103-2111. [CrossRef]

20. Bacanli, U.G.; Firat, M.; Dikbas, F. Adaptive Neuro-Fuzzy Inference System for drought forecasting. Stoch. Environ. Res. Risk Assess. 2008, 23, 1143-1154. [CrossRef]

21. Barros, A.P.; Bowden, G.J. Toward long-lead operational forecasts of drought: An experimental study in the Murray-Darling River Basin. J. Hydrol. 2008, 357, 349-367. [CrossRef]

22. Cutore, P.; Di Mauro, G.; Cancelliere, A. Forecasting Palmer Index Using Neural Networks and Climatic Indexes. J. Hydrol. Eng. 2009, 14, 588-595. [CrossRef]

23. Karamouz, M.; Rasouli, K.; Nazif, S. Development of a Hybrid Index for Drought Prediction: Case Study. J. Hydrol. Eng. 2009, 14, 617-627. [CrossRef]

24. Marj, A.F.; Meijerink, A.M.J. Agricultural drought forecasting using satellite images, climate indices and artificial neural network. Int. J. Remote Sens. 2011, 32, 9707-9719. [CrossRef]

25. Mishra, S.S.; Nagarajan, R. Forecasting drought in Tel River Basin using feedforward recursive neural network. In Proceedings of the International Conference on Environmental, Biomedical and Biotechnology, Dubai, UAE, 4 August 2012; Volume 41, pp. 122-126.

26. Belayneh, A.; Adamowski, J.F.; Khalil, B. Short-term SPI drought forecasting in the Awash River Basin in Ethiopia using wavelet transforms and machine learning methods. Sustain. Water Resour. Manag. 2015, 2, 87-101. [CrossRef]

27. Vidyarthi, V.K.; Jain, A. Knowledge extraction from trained ANN drought classification model. J. Hydrol. 2020, 585, 124804. [CrossRef] 
28. Khan, M.H.; Muhammad, N.S.; El-Shafie, A. Wavelet-ANN versus ANN-Based Model for Hydrometeorological Drought Forecasting. Water 2018, 10, 998. [CrossRef]

29. Qasem, S.N.; Samadianfard, S.; Kheshtgar, S.; Jarhan, S.; Kisi, O.; Shamshirband, S.; Chau, K.-W. Modeling monthly pan evaporation using wavelet support vector regression and wavelet artificial neural networks in arid and humid climates. Eng. Appl. Comput. Fluid Mech. 2019, 13, 177-187. [CrossRef]

30. Belayneh, A.; Adamowski, J.; Khalil, B.; Ozga-Zielinski, B. Long-term SPI drought forecasting in the Awash River Basin in Ethiopia using wavelet neural network and wavelet support vector regression models. J. Hydrol. 2014, 508, 418-429. [CrossRef]

31. Alsumaiei, A.A. Monitoring Hydrometeorological Droughts Using a Simplified Precipitation Index. Climate 2020, 8, 19. [CrossRef]

32. Al-Rashed, M.; Aliewi, A. Water resources sustainability in Kuwait against United Nations Sustainable Development Goals. In Sustainability in the Gulf; Informa UK Limited: Routledge, UK, 2017; pp. 37-56.

33. Alhumoud, J.M.; Al-Ruwaih, F.M.; Al-Dhafeeri, Z.M. Groundwater quality analysis of limestone aquifer of Al-Sulaibiya field, Kuwait. Desalination 2010, 254, 58-67. [CrossRef]

34. Mukhopadhyay, A.; Al-Awadi, E.; Quinn, M.; Akber, A.; Al-Senafy, M.; Rashid, T. Ground Water Contamination in Kuwait Resulting from the 1991 Gulf War: A Preliminary Assessment. Ground Water Monit. Remediat. 2008, 28, 81-93. [CrossRef]

35. Al-Sulaimi, J.; Viswanathan, M.N.; Székely, F. Effect of oil pollution on fresh groundwater in Kuwait. Environ. Earth Sci. 1993, 22, 246-256. [CrossRef]

36. Kozłowski, E.; Kowalska, B.; Kowalski, D.; Mazurkiewicz, D. Water demand forecasting by trend and harmonic analysis. Arch. Civ. Mech. Eng. 2018, 18, 140-148. [CrossRef]

37. Alhumoud, J.M.; Behbehani, H.S.; Abdullah, T.H. Wastewater Reuse Practices in Kuwait. Environmentalist 2003, 23, 117-126. [CrossRef]

38. Almedeij, J. Modeling Rainfall Variability over Urban Areas: A Case Study for Kuwait. Sci. World J. 2012, 2012, 1-8. [CrossRef]

39. McKee, T.B.; Doesken, N.J.; Kleist, J. The relationship of drought frequency and duration to time scales. In Proceedings of the 8th Conference on Applied Climatology; American Meteorological Society: Boston, MA, USA, 1993; Volume 17, pp. 179-183.

40. ASCE Task Committee on Application of Artificial Neural Networks in Hydrology. Artificial neural networks in hydrology. I: Preliminary concepts. J. Hydrol. Eng. 2000, 5, 115-123.

41. Nourani, V.; Mogaddam, A.A.; Nadiri, A.O. An ANN-based model for spatiotemporal groundwater level forecasting. Hydrol. Process. 2008, 22, 5054-5066. [CrossRef]

42. Kisi, O. Streamflow Forecasting Using Different Artificial Neural Network Algorithms. J. Hydrol. Eng. 2007, 12, 532-539. [CrossRef]

43. Adeloye, A.J.; De Munari, A. Artificial neural network based generalized storage-yield-reliability models using the Levenberg-Marquardt algorithm. J. Hydrol. 2006, 326, 215-230. [CrossRef]

44. Alsumaiei, A.A. A Nonlinear Autoregressive Modeling Approach for Forecasting Groundwater Level Fluctuation in Urban Aquifers. Water 2020, 12, 820. [CrossRef]

45. Alsumaiei, A.A. Utility of Artificial Neural Networks in Modeling Pan Evaporation in Hyper-Arid Climates. Water 2020, 12, 1508. [CrossRef]

46. Nash, J.E.; Sutcliffe, J. V River flow forecasting through conceptual models part I-A discussion of principles. J. Hydrol. 1970, 10, 282-290. [CrossRef]

47. Almedeij, J. Long-term periodic drought modeling. Stoch. Environ. Res. Risk Assess. 2015, 30, 901-910. [CrossRef]

48. AlRashidi, M.S.; Bailey, R.T. Estimating groundwater recharge for a freshwater lens in an arid region: Formative and stability assessment. Hydrol. Process. 2019, 34, 1063-1080. [CrossRef]

(C) 2020 by the authors. Licensee MDPI, Basel, Switzerland. This article is an open access article distributed under the terms and conditions of the Creative Commons Attribution (CC BY) license (http://creativecommons.org/licenses/by/4.0/). 